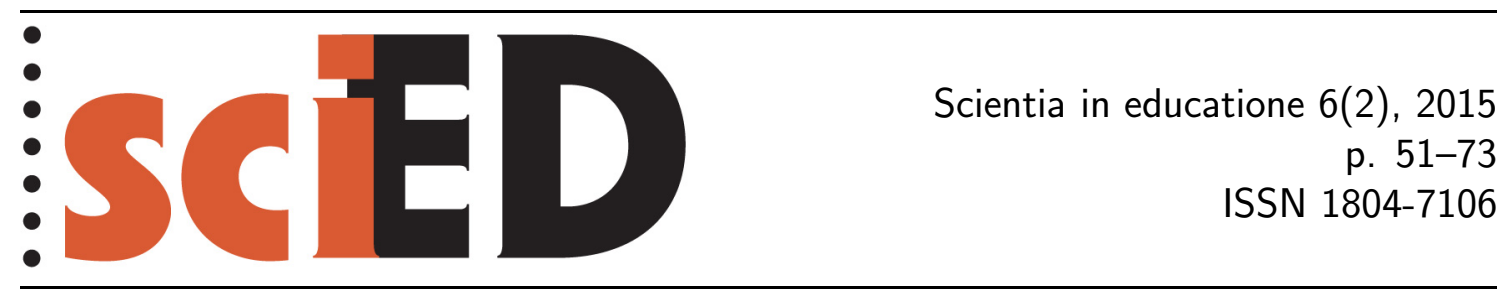

\title{
Omega Position - a specific phase of perceiving the notion of infinity
}

\author{
Jiři Cihlár̆, Petr Eisenmann, Magdalena Krátká
}

\begin{abstract}
This article describes a specific phase of the ontogenetic development of understanding infinity, called the omega position, the identification of which is one of the results of extensive research focusing on the perception of the infinity notion. Some 1432 Czech pupils and students between the ages of 8 to 20, participated in the first two sections of this research between the years 2008 and 2011. This article describes in more detail, the final qualitative part of the research that focuses on interviews with university students with the aim of diagnosing this phase in their perception of infinity in various contexts. It also describes some possibilities for the identification of the omega position and its consequences for a successful study of those notions and ideas of mathematics, which are associated with infinity. Further, the article puts the omega position into context with potential or actual infinity, specifies individual developmental phases by means of the notion horizon and explains some possibilities for mutual interference in the abovementioned developmental phases, employing the following two notions: that of primary and secondary intuition.
\end{abstract}

Key words: infinity, potential infinity, obstacle, horizon, improper number.

\section{Pozice Omega - specifická fáze vnímání pojmu nekonečno}

\begin{abstract}
Abstrakt
Článek popisuje specifickou fázi ontogenetického vývoje porozumění nekonečnu nazývanou pozice omega, jejíž identifikace je jedním $\mathrm{z}$ výsledků rozsáhlého výzkumu zaměřeného na vnímání pojmu nekonečno. Prvních dvou částí výzkumu se v letech 2008 až 2011 postupně zúčastnilo celkem 1432 českých žáků a studentů ve věku od 8 do 20 let. V článku je podrobně popsána závěrečná kvalitativní část výzkumu zaměřená na interview s vysokoškolskými studenty s cílem diagnostikovat tuto fázi v jejich pojetí nekonečna v různých kontextech. Článek popisuje možnosti identifikace pozice omega a její konsekvence pro úspěšné studium těch pojmů a idejí matematiky, které jsou spjaty s nekonečnem. Dává ji dále do souvislosti s potenciálním a aktuálním nekonečnem, vymezuje jednotlivé vývojové fáze pomocí pojmu horizont a vysvětluje možnosti vzájemného ovlivňování zmíněných vývojových fází s využitím pojmů primární a sekundární intuice.
\end{abstract}

Klíčová slova: nekonečno, potenciální nekonečno, překážka, obzor, nevlastní číslo. 
The concept of infinity is fundamental to mathematics and the teaching thereof (Fischbein, 2001; Tall \& Tirosh, 2001). During the course of the history of mathematics, the development of aspects of knowledge surrounding infinity has created crucial turning points essential for its further development. Not only for that reason the modelling of the development of understanding infinity by an individual is also an essential issue in the didactics of mathematics. In our research, which has been carried out since 2008 and focuses on the understanding of infinity in students aged between eight years and their university studies in a great number of differing contexts, we are endeavouring to describe this process of overcoming obstacles, specifically the epistemological and didactical ones (Cihlář, Eisenmann \& Krátká, 2013).

The previous research activities were focused, to a large extent, on more concrete contexts, such as the structure of number domains (Winter \& Voica, 2008; Ely 2010; Bauer, 2011) and on questions concerning the number $0 . \overline{9}$ (Katz \& Katz, 2010; Yopp, Burroughs \& Lindaman, 2011), as well as functions and limit processes (Juter, 2006; Monaghan 2001; Kidron \& Tall, 2015), comparisons of infinite sets (Jahnke, 2001; Tsamir, 2001) and a geometric context (Fischbein, 2001; Jirotková \& Littler, 2004). All of them, however, mostly refer to the difficulties students have while passing from 'the finite' to 'the infinite' and they all agree upon the basic role played by the initial intuitive ideas (Fischbein 2001; Jahnke, 2001; Dubinsky et al., 2005a, 2005b; Kidron, 2011). Jahnke (2001: p. 194) claims that "[students'] initial intuition is not really wrong, but applies only to a limited domain, whereas in other domains, new intuitions must be formed." A number of authors demonstrate the relationship between the difficulties students are confronted with during the learning process and the 'breakneck' historical development within a given area of mathematics (Katz et al., 2000). However, Dubinsky et al. (2005a, 2005b) place emphasis on the existence of a close relationship between the essence of mathematical concepts and their development in the mind of an individual and therefore, if we wish to help students overcome some difficulties in the comprehension of infinity, the first step is to understand the essence of all these mechanisms.

One of the motives of our research was our belief that the present day view of school education reflects insufficiently some specific features of the process of forming proper views of the phenomena associated with infinity. The lack of stimuli confirms, among other things, even an inadequate representation of suitable problems and exercises in textbooks.

In this paper we provide a detailed analysis of one phase of the development of an individual's conception of infinity - the omega position, by means of which some students intuitively work with sorts of 'improper' numbers or points and other infinitely small or infinitely large objects. During the course of our research, we rely on the generally accepted concept of the cognitive structure in (Piaget, 1977). While analysing an individual's journey, beginning with primary ideas and progressing to ideas close to the ideal mathematical concepts, we construct our considerations based on the theory of obstacles (Brousseau, 1997; Brousseau \& Sarrazy, 2002) and that of the cognitive conflict (Cihlár et. al., 2009) on the one hand, and the theory of the position of the horizon (Vopěnka, 2011) on the other.

\section{THEORETICAL BACKGROUND}

\subsection{THE THEORY OF OBSTACLES AND COGNITIVE CONFLICT}

In a wider context, we assume that an individual builds the cognitive structure by means of concept images "that are associated with the concept which includes all 
the mental pictures and associated properties and processes" (Tall, 2002: p. 6), including primary and secondary intuition ${ }^{1}$ (Fischbein 1987; Singer \& Voica, 2008) and tacit models ${ }^{2}$ (Fischbein, 2001; Kidron, 2011).

An obstacle is comprehended as a set of items surrounding knowledge, firmly anchored in an individual's knowledge structure, which can be, under certain circumstances, successfully employed. However, this can both fail and produce bad results in a new context (Krátká, 2010). For successful formation of further ideas, it is necessary to overcome this obstacle, i.e. to distinguish which knowledge is transferable into the new context and which is not; and how to alter it so that it can be utilised yet again in a new context (Brousseau, 1997). In our research, we have focused on the obstacles of the didactic origin, in particular those of epistemological origin.

The cognitive conflict is understood as a conscious discrepancy in the individual's cognitive structure. Since "only when conflicting aspects are evoked simultaneously need there be any actual sense of conflict or confusion" (Tall \& Vinner, 1981: p. 152). For us, the cognitive conflict has become a tool for the identification and description of obstacles while forming the individual's notions about infinity in this research. However, inducing cognitive conflicts is simultaneously crucial for overcoming the obstacles that may occur in the teaching and learning process. Our elaboration on the theory of the cognitive conflict for this purpose is covered in detail in (Cihlár et al., 2009). In connection with the concept of infinity, Tall $(1976,1977)$ speaks about the cognitive conflict and Swan (1983) mentions the so-called cognitive conflict teaching approach as well in connection with a comparison of infinite sets.

The concept of cognitive conflict is also utilized within the framework of the APOS theory, which is based on Piaget's thoughts concerning the existence of a close relationship between the quality of the mathematical concept and the development of the individual's mind (Dubinsky et al., 2005a).

The ideas emerging from the Piaget theory of developmental stages are resumed by the theory of epistemological obstacles. This theory presumes that the construction of knowledge is not determined only by positive stages, as formulated by Piaget and Garcia, but also by means of negative stages, including various rules, convictions and ways of reasoning that create obstacles for those changes leading to further stages (Sierpinska, 1994).

\subsection{THEORY OF HORIZON}

The discovery of how one or another pupil perceives the existence of objects investigated by science, plays a key role in the analysis of the development of an

\footnotetext{
${ }^{1}$ Fischbein distinguished between primary and secondary intuitions. Primary intuition is "developed in individuals independently of any systematic instruction as an effect of their personal experience" (Fischbein, 1987: p. 202). Secondary intuitions are acquired, not through experience, but through some educational interventions, when formal knowledge becomes immediate, obvious, and accompanied by confidence. They are completely in line with the formal theory. Fischbein explained, for instance, that "if for a mathematician the equivalence between an infinite set and a proper subset of it becomes a belief - a self-explanatory conception - then a new, secondary intuition has appeared" (Fischbein, 1987: p. 68).

${ }^{2}$ Fischbein (2001: p. 328) explains the role of tacit models as follows: "Sometimes, mental models are used intentionally, consciously, but sometimes we are not aware of their presence and/or of their impact. ... The model brings with it also properties which are not relevant for the original. Tacit models, being uncontrolled consciously, may lead to distorted interpretations and conclusions."
} 
individual's conception of infinity. The difference in modalities of the being of real or ideal objects, must be taken into account during the course of the process of learning.

Another important basis for our analysis of the development of individual's ideas about infinity, is the conception of the horizon and changes of its position (Krátká, 2010). The horizon is explained as the line separating the illuminated part of an observed object from the unilluminated. In addition to that, the horizon itself is a subjective concept - it is a boundary of our viewing capabilities, whether as a view in the sensual sense or a 'view extended by knowledge' (Vopěnka, 2011). Mathematics as a science has been working with the ideal only since the antique time, i.e. infinity as clearly characterized and independent of an individual. By contrast, an individual grasps this concept by means of both "natural thinking builds from concept imagery towards formalism" and "formal thinking builds from the concept definition, marginalizing imagery and focusing on logical deduction" (Tall, 2001: p. 235). An individual may view a set or an object as infinite, if it stretches as far as its horizon. In this case, we speak about so-called natural infinity. If we reach beyond a horizon, it means that we will extend the visible part and what previously appeared to have been infinite, is no longer the case.

Ideal infinity is the sharpening of natural infinity, similarly to the thinning and straightening of a drawn straight line. The sharpening of the given large set will also result in the emergence of ideal infinity (Vopěnka, 2011). If we apply Tall's thinking (2001: p. 235) that there are "natural concepts of infinity, developed from experience in the finite world, and formal concepts of infinity, derived from formal definitions and deductions", then, expressed in a simplified way, the child forms the concept of natural infinity by means of the first way, when the individual's ideas based in their primary intuition. Beside that the concept of ideal infinity is formed in both ways in which primary and secondary intuitions are employed.

On this route, an individual reaches certain (developmental) phases, which are dealt with in the next chapter.

\section{CONCEPTIONS OF INFINITY}

It is common for the didactics of mathematics to work with the notions of potential infinity and actual infinity, which represent two significant stages in the development of mathematics, as well as two phases in the development of pupils' understanding. As Kidron and Tall (2015: p. 186) write, "since Greek times, the natural conception of infinity is the concept of potential infinity, including the unlimited possibility of counting or the possibility of dividing an interval into successively smaller parts". Similarly, it seems to Singer and Voica (2008: p. 200) that "potential infinity is functional and natural in children". A long line of studies deals with circumstances of this development from the potential conception of infinity to the actual conception. These ideas are supported by Tall and Tirosh (2001: p. 131), who mention that "This 'never-ending struggle' with potential infinity of the process proved to offer a serious cognitive obstacle to students' understanding of the limit concept." Similarly, Kidron and Tall (2015: p. 192) focused their research on "students' ability to make a transition from the potentially infinite process view to the concept of infinite sum and on towards the formal definition of limit".

We assume that it is essential to take into consideration even the primary phase of natural infinity and pay attention to the specific phenomenon we started to call 
the omega position, in order to achieve a better understanding of the development of students' notions of infinity.

The following model of the developmental structure thus contains four types of conceptions, including formal actual infinity, which corresponds to the understanding of present-day school mathematics. The above-depicted classification, however, cannot be perceived in such a simplified manner that the respondent has one conception of infinity in all contexts.

The simplest and the earliest conception of infinity, which we encounter with our respondents, is natural infinity. Natural infinity is a subjective phenomenon - a set or an object may appear naturally infinite to individuals if it reaches as far as their horizon. If we perceive sets as classically actual infinite (in the sense of the classical set theory), the individual's horizon lies within its framework and is immovable. For instance, natural numbers in the individual's perception ended with the largest immovable natural number (for instance a trillion, etc.). The straight line in their minds is identified with its image - i.e. the segment.

Potential infinity is a more advanced concept. The respondent is already aware of the possibility that an arbitrary horizon can be surpassed; that his/her horizon is therefore movable, but it still lies within the discussed set, which is understood as a classically actual infinite set by us. Natural numbers in his/her mind set still end with the largest natural number, whereby the actual size of which is unknown to us. The straight line here is understood as a segment that can be limitlessly extended in compliance with the Euclidian conception.

The term actual infinity is used to designate the situation in which all horizons have already been broken through and the respondent disposes of notions of contemporary school mathematics in the field of infinity.

However, there exists a group of learners/students that is not inconsiderable, the ideas of which it is impossible to include in either of the above-described phases. For instance, the set of natural numbers is extended by an 'improper' natural number, which is bigger than all other natural numbers. This number (the respondent calls it 'infinity') has some qualities of numbers - for instance, it designates the number of elements of a set, but it also lacks some qualities - for instance the possibility the addition of another number. Similarly, the straight line is extended as far as 'infinity' but it preserves its boundary (improper) point, so it is understood as an 'infinite segment'. Kidron and Tall (2015) in their study concerning visualisation and symbolism in the limit process categorized four types of students' approaches to the concept of the infinity sum of functions. Category I, II, and IV could be successfully compared to the above-mentioned three phases. Category III, within which $28 \%$ of the interviewed university students fell, is characterised by the following statement: "The infinite sum of functions is perceived as a legitimate object but not clearly as the formal limit definition. The student views the infinite polynomial as a legitimate object but does not yet fully grasp ... a formal definition of the actual infinite sum" (Kidron \& Tall, 2015: p. 194). A part of these students "perceives the infinite sum as a generic limit object" (Kidron \& Tall, 2015: p. 194), what is a limiting object conceived as having the same properties as the objects in the limiting process (Tall, 1991, 2009).

It is interesting that some learners in that phase of their understanding of infinity intuitively anticipate mathematical ideas that are precisely expressed in the other mathematical disciplines (the theory of ordinal numbers, non-standard analysis (Robinson, 1996), the Conway theory of games and numbers (Conway, 2001), projective geometry, etc.) and intuition, they base their considerations on, is on the 
one hand secondary, as it is influenced by the teaching surrounding actual infinity, and on the other hand also primary, as it is possible to arrive at such considerations by means of sharpening potential infinity and the subsequent transition of their horizons. However, these learners usually work only with the idea of 'one' infinity, but in two forms - i.e. 'infinitely large' and 'infinitely small' (Katz \& Katz, 2010).

We consider the above-named phase of the individual's ideas another developmental phase in the understanding of infinity (apart from natural, potential, and actual infinity) and employ the term omega position for its designation. The term was chosen as the set of natural numbers and ordinal number omega make an appropriate approximation of students' idea of improper element.

\section{RESEARCH GOALS AND HYPOTHESES}

Based on the first two parts of research we suppose that a considerable portion of secondary school students and fresh university students find themselves in the phase of potential infinity or they are at the omega position. This understanding of infinity thus can become an obstacle in the course of their learning basic terms associated with the infinity phenomenon (for instance the limit of a sequence and a function, sum of an infinite series). We are convinced that by means of diagnostics of these phases the teacher will be able to solve more effectively the problems of these students, which can be different in both the named phases. The teachers can easily identify some manifestations of students who find themselves in the phase of potential infinity. The omega position, however, is unknown for them. For that reason, we have formulated the main goals of our research as follows:

- To determine proportional representation of students between the ages of 12 and 18, who have already overcome the primary phase of natural infinity and at the same time are not in the phase of actual infinity, depending on the context.

- To create a tool for the identification of the omega position in all contexts and views.

The following hypotheses are associated with the marked goals:

H1: A significant portion of fresh university students find themselves in the omega position.

H2: Students get to the omega position when forced by the new context to change their potential approach to infinity, to the actual approach.

\section{THE EXPERIMENT}

The research was carried out in three parts.

\subsection{INTERVIEWS WITH PUPILS}

In the first place, during the course of 2008 we conducted guided experimental interviews with respondents from six age categories: 8, 10, 12, 14, 16 and 18 years old, selected by our team. These were always been students of ordinary primary and secondary schools. In each age category four students were interviewed. The following were the criteria for the selection of the respondents: the average or above-average school assessment in mathematics and their ability to communicate in mathematics classes; with both cases being evaluated by the teacher. 
The interviews were recorded by a video camera. These recordings were, after their transcription into reports, analysed in great detail by the whole research team. We concentrated primarily on the formulation of the obstacles in the understanding of infinity and the process of their overcoming. When constructing approximate scenarios from experimental dialogues, we applied a method resulting from the constructed reactions of the pupils, which means that our team of researchers was attempting to prepare for all possible variants whilst predicting in which ways our dialogue with pupils on the given theme might be developing. While analysing our interviews, we were monitoring the process of inducing the cognitive conflict and attempts to remove it.

This section of the research resulted in the primary formulation of some of the epistemological obstacles the learners meet during the course of their creation of notions associated with infinity. Another goal of this part of our research was to elaborate the questionnaire of the highest possible quality for the subsequent section of this research.

\subsection{The QUESTIONNAIRE SURVEY}

Secondly, we were trying to find out, by means of a mass questionnaire survey, the initial reactions of pupils solving the tasks that necessitate ideas associated with the infinity concept. The key goal here was to identify the main sources of obstacles in the understanding of the notion of infinity and the epistemological obstacles arising from the process of creating this notion.

During the course of 2009, the questionnaire survey was carried out on a total number of 1388 primary and secondary school students from six age categories (8, $10,12,14,16$ and 18 years old) at various types of schools ${ }^{3}$. The individual schools and classes were selected with aim of gaining the most representative sample data. The respondents answered in writing and anonymously. This research used different learners from those used in the first part of the research. A detailed survey of individual groups of respondents and detailed description of the methodology are presented in (Cihlář, Eisenmann \& Krátká, 2013).

This part of the research has resulted in the identification of the following two main sources of obstacles in the understanding of infinity: the conception of the existence of objects and positions of the horizon. Further, we have distinguished 15 epistemological obstacles in the process of creating the infinity concept divided into four groups: knowledge about finite sets, replacement of an object by its model, knowledge about finite processes and knowledge about the set of natural numbers (Cihlářr, Eisenmann \& Krátká, 2013).

\footnotetext{
${ }^{3}$ The Czech Republic school system: Primary education lasts for a period of nine years and is divided into two stages: i.e. a 5-year stage (from the age of 6 until the age of 11) and a 4year stage (from the age of 11 until the age of 15). Some of the primary schools focus on the teaching of gifted children, i.e. selective language schools, eight-year secondary grammar schools and schools with extended instruction in mathematics. In this article students up to the age of 15 will be designated as primary school students. Secondary education comprises three main types of schools: secondary general schools (grammar schools), secondary technical and business schools and secondary vocational schools. Schools of this type will be called high schools. Grammar schools prepare students for their further studies at institutions of higher education. The above mentioned secondary technical schools and numerous 4-year courses at secondary vocational schools prepare students for a wide range of professions, as well as for further studies at institutions of higher education. The 2-year and 3-year courses at Czech vocational schools prepare students for a great variety of professional activities.
} 


\subsection{INTERVIEWS WITH UNIVERSITY STUDENTS}

When analysing the results of the first two parts of our research, we came across the phenomenon of the omega position, which has already been mentioned above. For that reason, we returned to individual interviews from the first part of the experiment and, in particular, to the questionnaires from the second part. The results have then been processed and evaluated, the omega position signs described in both arithmetical and geometrical contexts, and that is from the point of view of distance as well as depth. We focused hereby on the interview and questionnaire items that indicate that the respondent may be in that phase.

As university teachers, we also asked ourselves whether in that phase of the perception of infinity, there could also be new university students. Based on some relevant items in the questionnaire we therefore compiled a scenario of our interviews and during the course of the years from 2012 to 2013, carried out these interviews with 20 university students from the first year of Jan Evangelista Purkyně University in Ústí nad Labem. Those were students of technical branches of study and those studying natural sciences with the exception of mathematics. When the interview was undertaken the students had been studying the basic course in mathematics for one or two months. The course usually lasts two semesters at the school of economics, as well as those studies of technical and natural scientific orientation. The students were not selected on a compulsory basis; they took part in the interview voluntarily, on the basis of a call for participants. Ten of them were interviewed separately; the remaining ten were asked selected questions in pairs. The interview with students was always conducted by the same person of our research team. The Interviewer always made a report at the end of each interview and this report was subsequently analysed by the entire research team. The whole interview lasted approx. 45 minutes. The interview scenario is described in the introductory part of chapter 5.2.

\section{Results AND DisCUSSION}

\subsection{ThE QUESTIONNAIRE SURVEY}

Six items had been selected from all the questionnaire items ${ }^{4}$, those which enabled us to determine reliably by means of selected answers on the one hand about the respondent's not being in the phase of natural infinity (NI) anymore, since its horizon is immovable anymore, and at the same time the respondent being located in the phase of actual infinity (AI), as their horizons have already been broken through. However, based on the primary reaction we were not able to decide on the respondent's being at the phase of potentional infinity (PI), or at the phase of the omega position (OP).

With all subsequent items, the phase of actual infinity is signallized by the respondent's negative response of the following type: "Such a number does not exist.", or "Such a point doesn't exist." The phase of potential infinity or the omega position was identified according to the specific answers that followed.

\footnotetext{
${ }^{4}$ The complete questionnaire can be found as additional material on the magazine's web site. The questionaire had slightly differrent versions according to the respondents' age.
} 
Task 4 (MAXIMNUMBER): What is the largest number?

Answers:

- " $\infty "$

- "Infinity"

Task 14 (EVENLIMIT): The numbers 2, 4, 6, 8, 10, . . are constantly increasing. Determine the largest number that can be obtained in this manner.

Answers:

- " $\infty$ "

- "Infinity."

- "Infinite multiple of two."

Task 2 (MINIMPOSITIV): What is the smallest number bigger than zero? Answers:

- "0.0 . . $01^{\prime \prime}$

- " $0 . \overline{0} 1 "$

Task 13 (RATIOLIMIT): The numbers $\frac{1}{1}, \frac{1}{2}, \frac{1}{3}, \frac{1}{4}, \frac{1}{5}, \ldots$ are constantly decreasing. Determine the smallest number that can be obtained in this manner.

Answers:

- "0.0 ..01"

- " $0 . \overline{0} 1 "$

- " $\frac{1}{\infty} "$

Task 7 (MAXIMDISTANCE): There is a given straight line $b$ and the point $A$, which does not lie on this line. Construct segment $A B$ with the point $B$, which lies on the given straight line $b$ with the segment $A B$ as long as possible.

Fig. 1: Assignment of Task 7 MAXIMDISTANCE

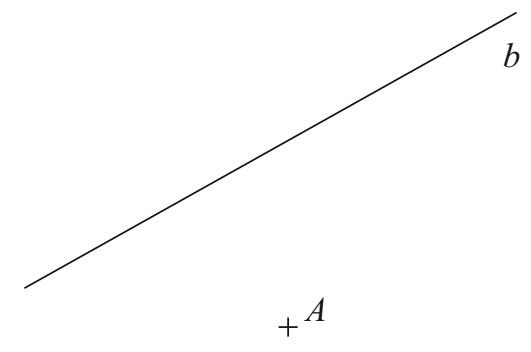

Answers:

- " $B$ is in infinity."

- " $B$ is at the end of the line."

- A parallel line is suggested.

Task 8 (AREASQMIN): Here is the square $A B C D$. Find the point $X$ on its $B C$ side so that the triangle $A B X$ will have the smallest possible area.

Answers:

- "It will be close above point $B$ " or it is drawn in this sense.

- "As close to point $B$ as possible."

- $X$ is drawn a bit above $B$. 
Tab. 1: Division of items according to the context and the kind of viewpoint

\begin{tabular}{lll}
\hline & Arithmetical context & Geometrical context \\
\hline View into the distance & MAXIMNUMBER & MAXIMDISTANCE \\
& EVENLIMIT & \\
\hline View into the depth & MINIMPOSITIV & AREASQMIN \\
& RATIOLIMIT & \\
\hline
\end{tabular}

Tab. 2: Observed frequencies with the following items: Task 4 MAXIMNUMBER and Task 14 EVENLIMIT

\begin{tabular}{llrrrr}
\hline \multirow{2}{*}{ observed frequencies } & & \multicolumn{2}{c}{ EVENLIMIT } & \multirow{2}{*}{ Sum } \\
\cline { 2 - 5 } & & Others & AI & PI or OP & \\
\hline \multirow{2}{*}{ MAXIMNUMBER } & Others & $\mathbf{1 9 1}$ & 13 & 103 & 307 \\
\cline { 2 - 5 } & AI & 78 & $\mathbf{2 9}$ & 65 & 172 \\
\cline { 2 - 5 } & PI or OP & 154 & 9 & $\mathbf{3 4 0}$ & 503 \\
\hline Sum & & 423 & 51 & 508 & 982 \\
\hline
\end{tabular}

Tab. 3: Expected frequencies in the following items: Task 4 MAXIMNUMBER and Task 14 EVENLIMIT

\begin{tabular}{llrrrr}
\hline \multirow{2}{*}{ expected frequences } & & \multicolumn{3}{c}{ EVENLIMIT } & \multirow{2}{*}{ Sum } \\
\cline { 2 - 5 } & & Others & AI & PI or OP & \\
\hline \multirow{3}{*}{ MAXIMNUMBER } & Others & $\mathbf{1 3 2 . 2 4 1 3}$ & 15.94399 & 158.8147 & 307.0000 \\
\cline { 2 - 6 } & AI & 74.0896 & $\mathbf{8 . 9 3 2 ~ 7 9}$ & 88.9776 & 172.0000 \\
\cline { 2 - 6 } & PI or OP & 216.6690 & 26.12322 & $\mathbf{2 6 0 . 2 0 7 7}$ & 503.0000 \\
\hline Sum & & 423.0000 & 51.00000 & 508.0000 & 982.0000 \\
\hline
\end{tabular}

These six items can be classified according to the mathematical context and the kind of viewpoint into four kinds according to Tab. 1.

To be able to assess the reliability of our research, we investigated whether the given variants of answers correlate with one another. In all six items, apart from the above-mentioned variants in answers signalling the PI, OP or AI phases, we were monitoring also the other variants of answers. By means of the chi-square test for contingent tables were tested the hypothesis concerning the independence of the answers on the selected pairs of items. The detailed results are mentioned only for the first pair of Task 4 MAXIMNUMBER and Task 14 EVENLIMIT in Tab. 2 and 3 .

The null hypothesis of independence was rejected at the the level of significance being $1 \%$ (chi-square $=151834, \mathrm{~d} f=4, p=0.00000$ ). By comparing frequencies on the main diagonal in both the tables, it is evident that the observed frequencies are significantly higher than those expected with the answers that are independent.

Both the items have a statistically significant correlation between the corresponding variants of answers (Spearm. $R=0.308624, p=0.000000$ ).

The same result was observed in independence tests between the items in the arithmetical context with view to the depth, between the items on the arithmetical and geometrical contexts with both the views, as well as between the items with a view into the distance and into the depth in both the contexts - null hypotheses of independence were, in the majority of cases, rejected at the level of $1 \%$ significance.

Thus, it is possible to certify that the reliability of our research task is sufficient. 
Let us focus at first on the learners who have already overcome the phase of natural infinity and are therefore in one of further phases (PI, OP or AI). The relative frequency of the occurrence of corresponding variants of answers to individual questionnaire items in accordance with the learners' age can be found in the following two graphs - Fig. 2 and Fig. 3. Numeric data in the graphs are therefore only lower estimates for the percentage of students who have already overcome the phase of natural infinity.

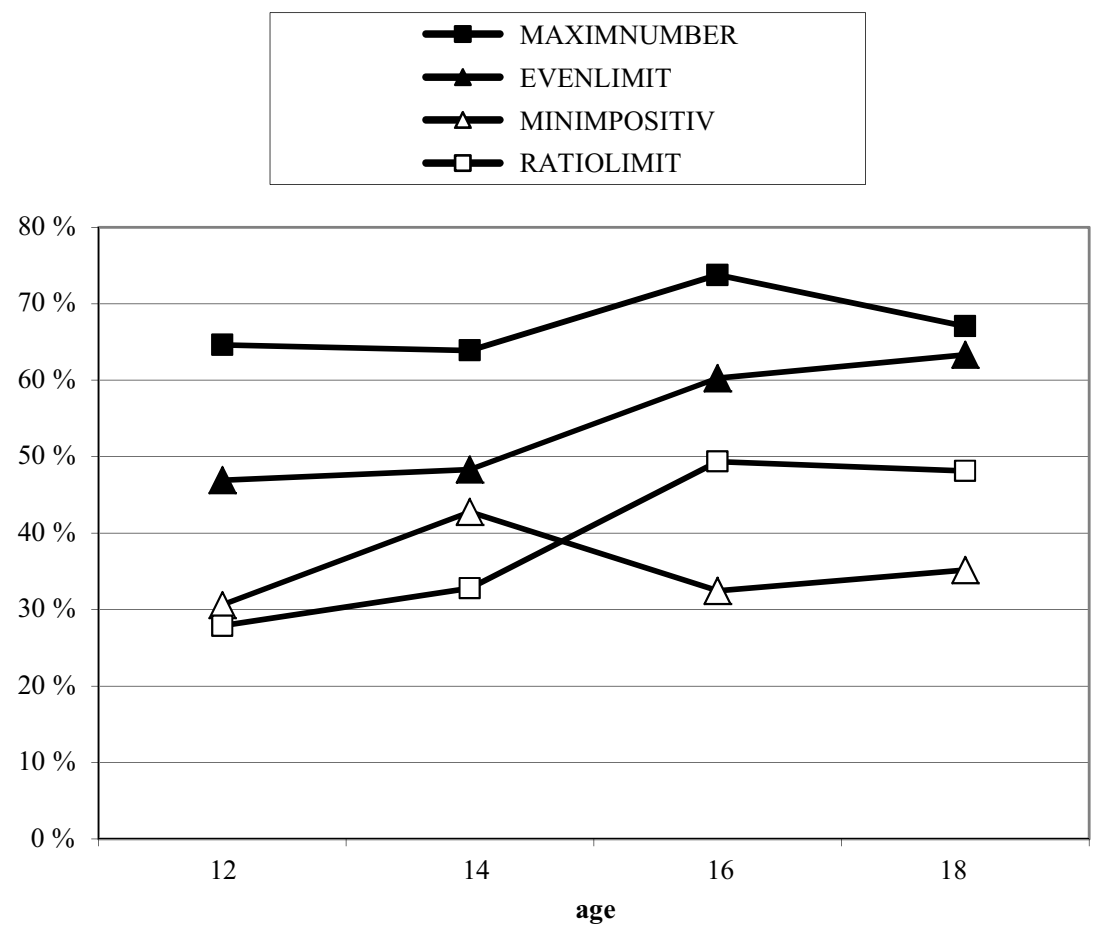

Fig. 2: View into the distance and into the depth in the arithmetical context

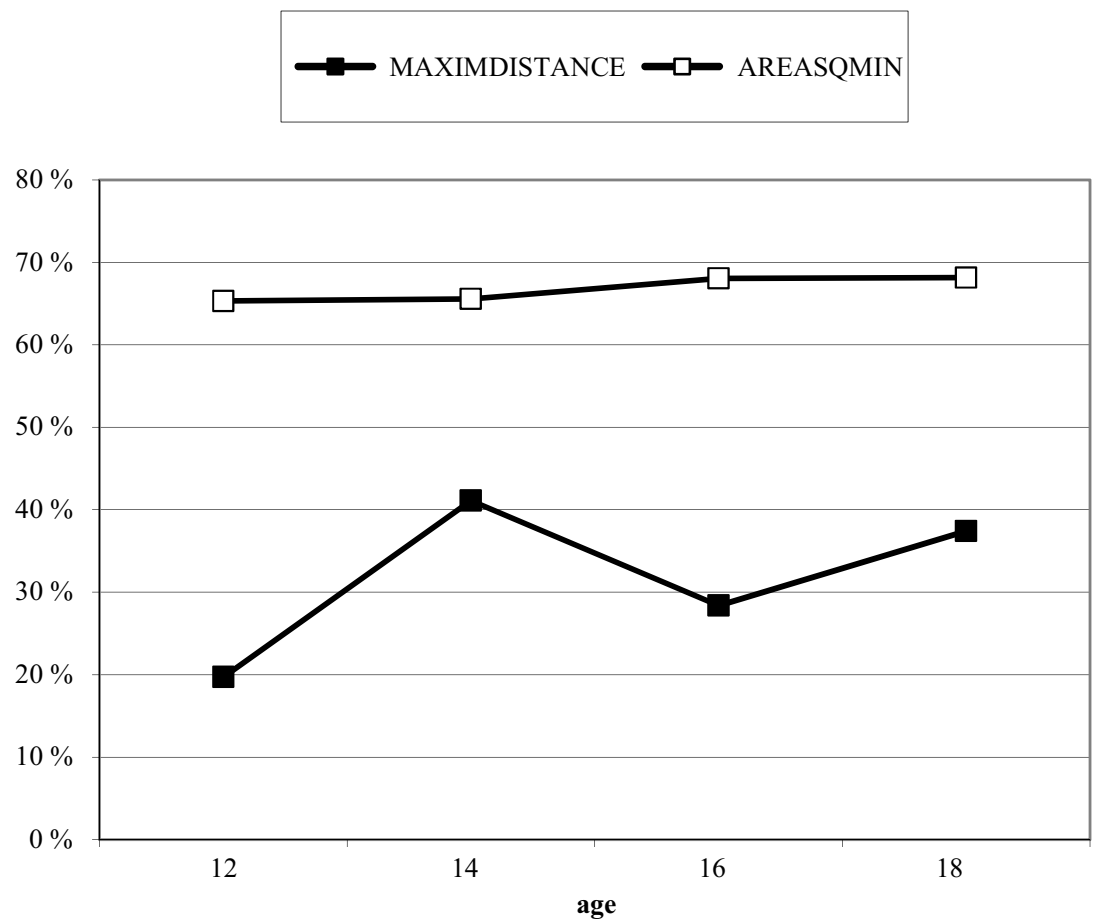

Fig. 3: View into the distance and into the depth in the geometrical context 
By means of comparison of the values from graph in Fig. 2, we usually find out that in the arithmetical context the phase of natural infinity, while applying the view into the instance (Task 4 MAXIMNUMBER and Task 14 EVENLIMIT), has already been overcome by more than one half of learners by the age of 12 , while by applying view into the depth (Task 2 MINIMPOSITIV and Task 13 RATIOLIMIT) approx. only less than one third of learners of this age have overcome the phase of natural infinity. Analogical conclusions can be drawn even in other age categories; with the difference in our estimates of the percentage of learners being more than $20 \%$. The ability to move the horizon into the distance starts to appear in learners in the arithmetical context much earlier than the ability to move the horizon into the depth. It is caused by the learners' coming into contact with natural numbers and their properties (in particular their getting larger) much earlier than with decimal or real numbers and their properties (in particular their getting smaller).

The situation in the geometrical context, more precisely in the situation when in the learners' imagination, a point moves to a straight line, is different. By comparing the values from graph in Fig. 3, it is evident that the phase of natural infinity while applying the view into the distance (Task 7 MAXIMDISTANCE) is overcome by fewer students in all age categories than when applying the view into the depth (Task 8 AREASQMIN). This can be caused by the fact that the learners have predominantly the experience with construction geometry, realized on a piece of paper (in the computer), where mutually close points in exercises and students' ideas occur quite frequently, while the necessity to think about very distant points arises only rarely. The view into the depth is not limited by paper, the view into the distance, on the contrary, is significantly limited. In addition to this, with a straight line a considerable number of learners replace an object by its model (Krátká, 2005). With the Task 7 MAXIMDISTANCE, approx. one third of learners draw the searched point, i.e. point $B$. at the end of the straight line. These learners cannot be unanimously identified as those who have already overcome the phase of natural infinity.

The following Tab. 4 shows the percentage of the learners who answer the following items by offering negative answers and these learners therefore are at the phase of actual infinity.

Tab. 4: The percentage of learners who are at the phase of actual infinity depending on their ages

\begin{tabular}{lrrrr}
\hline \multirow{2}{*}{ Item } & \multicolumn{4}{c}{ Age } \\
\cline { 2 - 5 } & \multicolumn{1}{c}{12} & \multicolumn{1}{c}{14} & 16 & 18 \\
\hline MAXIMNUMBER & $20 \%$ & $14 \%$ & $20 \%$ & $14 \%$ \\
\hline EVENLIMIT & $10 \%$ & $7 \%$ & $4 \%$ & $3 \%$ \\
\hline MINIMPOSITIV & $7 \%$ & $11 \%$ & $5 \%$ & $1 \%$ \\
\hline RATIOLIMIT & $10 \%$ & $7 \%$ & $4 \%$ & $2 \%$ \\
\hline MAXIMDISTANCE & $10 \%$ & $26 \%$ & $10 \%$ & $6 \%$ \\
\hline AREASQMIN & $6 \%$ & $9 \%$ & $5 \%$ & $1 \%$ \\
\hline
\end{tabular}

The values in the table show that the transition into the phase of actual infinity is the easiest in the arithmetical context when students apply the view into the distance. Surprising is the finding that with the exception of the first item all other items show the degressive trend in age categories 14 to 18 years. The apparent paradox that learners abandon their ideas about actual infinity can be explained also by their getting into the omega position. In this highly sensitive period of their age, they speak about infinity at school in different connections and contexts and secondary intuition starts forming in them. 
If we reduce the values from Fig. 2 and 3 by the values from Tab. 4 , we will get lower estimates for the percentage of the students who are at the phase of potential infinity or in the omega position. Seeing that our mistake in determining the relative frequency is approx. $3 \%$, it is possible to consider these dependencies on age, in the majority of cases, as nondecreasing (see Fig. 4 and Fig. 5).

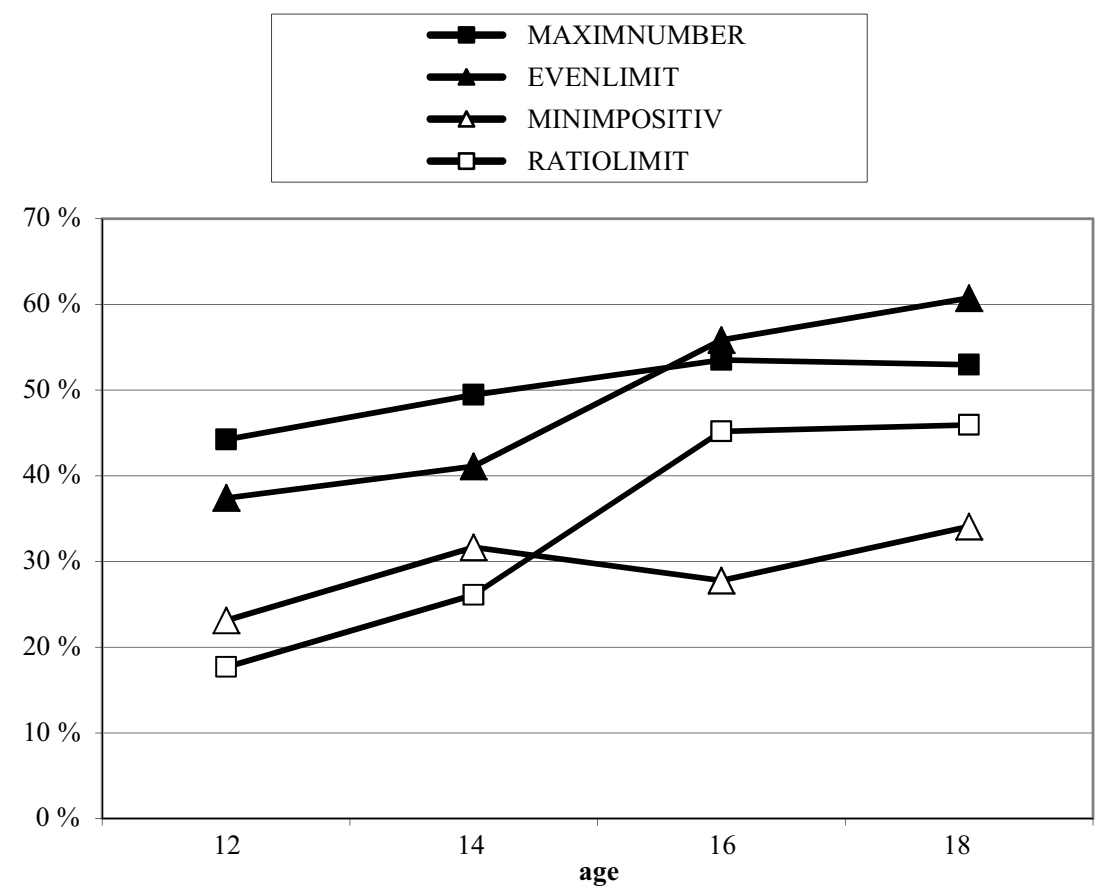

Fig. 4: View into the distance and into the depth in the arithmetical context

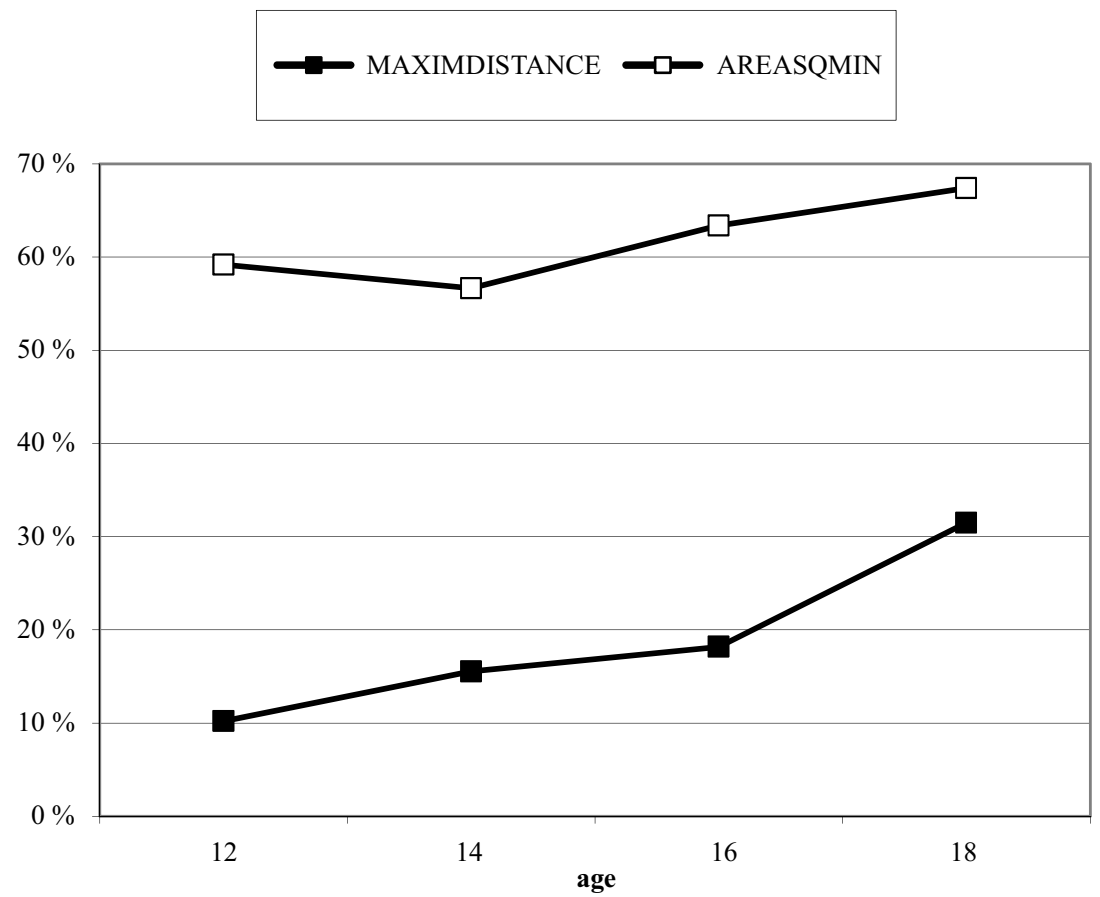

Fig. 5: View into the distance and into the depth in the geometrical context 
The variants of answers to the selected items of the questionnaire did not enable us to decide what number of respondents, whose percentages are indicated in Fig. 4 and 5 , is in the phase of potential infinity and which is in the omega position. The differentiation between these two phases was the subject of a further qualitative section of our research.

\subsection{INTERVIEWS WITH UNIVERSITY STUDENTS}

The scenario of these interviews set itself the aim of enabling in respondents to decide, in both the contexts and both the views, whether they find themselves in the phase of the omega position or not. The respondent used to be gradually given all six questions (or items of the questionnaire referred to in chapter 5.1). Apart from some exceptions, the primary reaction of the respondents was one of the answers described in the previous chapter. This indicates that respondents find themselves in the phase of potential infinity or whether they are at the omega position. The following lines then describe initiation questions with individual items. Their task was to induce the cognitive conflict. According to the way by means of which the respondent solved this conflict, it was possible to diagnose the omega position or to reject it. Each item or each pair of items is afterwards followed by the respondents' reactions and their interpretations.

Task 4 (MAXIMNUMBER): What number is the largest number?

Answers:

- " $\infty "$

- "Infinity."

Task 14 (EVENLIMIT): Numbers 2, 4, 6, 8, 10, .. are constantly increasing. Determine the largest number that can be obtained in this manner.

Answers:

- " $\infty "$

- "Infinity."

- "Infinite multiple of two."

Initiatory questions to both the items:

- "And what will you get when you multiply the infinity by two?"

- "And what will you get when you add one hundred to the infinity?"

When asked, two thirds of students responded that infinity again is the result. They used the following answers: "This is not changed any more.", "Infinity is the largest and there is nothing else behind it."

One third of the students mentioned as their first reaction that the result of the above-mentioned operations is a number larger than infinity, but after a short discussion the respondent was always brought to the cognitive conflict, the result of which was his revision of the original answer in the sense that infinity does not change, that it is the largest number behind which there is nothing else.

In the arithmetical context, while applying the view into the distance, the omega position prevails in respondents. The following two items focus on the view into the depth, still in the arithmetic context.

Task 2 (MINIMPOSITIV): What is the smallest number bigger than zero? Answers:

- "0.00...1"

- " $0 . \overline{0} 1 "$ 
Task 13 (RATIOLIMIT): Numbers $\frac{1}{1}, \frac{1}{2}, \frac{1}{3}, \frac{1}{4}, \frac{1}{5}, \ldots$ are constantly decreasing. Determine the smallest number, which can be obtained in this manner.

Answers:

- "0.00ldots1"

- " $0 . \overline{0} 1 "$

- " $\frac{1}{\infty} "$

Initiatory questions to both the items:

- "And what will you get when you multiply this number by number two?"

- "And what will you get if you multiply this number by ten?"

- "And what will you get when you divide this number by ten?"

At first, let us present the results of the students who answered $0.00 \ldots 1$ or $0 . \overline{0} 1$. Three quarters of students referred to the result $0.00 \ldots 2$ in their answers or they said that the decimal point would be moved only by one position to the right or that one zero would be added there. In the subsequent discussion, only one half of them expressed themselves in the sense that the above-mentioned operations have no influence on the result.

One quarter of the students answered immediately using the following words: "This will not change; there is an infinitely number of these noughts." Such an answer enables us to diagnose the omega position in these students.

As far as the answer $\frac{1}{\infty}$ with the RATIOLIMIT item is concerned, all eleven students who answered like that state that this number will not be changed in any way by the proposed operations and that it is the smallest positive number and it is not possible to make it bigger or smaller in any way.

In the arithmetical context, when applying the view into the depth it is possible to diagnose the omega position, roughly speaking, in one half of the respondents.

Let us complete these considerations by an analysis of answers of the selected students to the following item, which on the one side was part of the questionnaires, but its evaluation did not enable us, due to the absence of full answers, to decide which phase of the conceptions concerning infinity the respondents find themselves in. When discussing that issue the respondents were always extremely engaged.

Task 15 (PER09): It holds that $0 . \overline{9}<1$ or $0 . \overline{9}=1$ ? Explain why.

Answers:

- " $0 . \overline{9}$ is smaller because it never reaches one although it comes closer to it."

- " $0 . \overline{9}$ is smaller, because it never equals one even if there were an infinite number of nine digits."

Initiatory question:

- "You say that $0 . \overline{9}$ is smaller than 1 . What is then the difference between 1 and $0 . \overline{9}$, what does therefore the number $1-0 . \overline{9}$ equal?"

The majority of the students answered in the same way: "Zero point, and infinite number of noughts and at the end of that digit one." In the answer to such a question, it is possible to register the potential presence of the omega position. To distinguish with whom this phase really prevails, we asked the students the initiation question used in the previous items: "And what will you get, when you multiply this number by ten?"

We could observe two kinds of answers.

Some students usually answer in the following way: "Zero point zero, zero and the digit one will be shifted by one position to the left" (they point to the notation 
$0.0 \ldots 1$ in front of digit 1). The students who answered like this perceive this last decimal digit (here digit 1) as movable; i.e. they perceive the number of zeros between the first and the last digit only as potentially infinite.

In contrast to that, other students answer in this way: "It will be the same, there is an infinite number of zeros, and if I were to take one away, there would still be an infinite number of them." With these students, it is possible to identify the omega position in this situation.

This concept can be understood as a special case of the generic limit, what is a limiting object conceived as having the same properties as the objects in the limiting process (Tall, 1991, 2009). The number $0 . \overline{0} 1$ is bigger than 0 , just like all members of the sequence $0.1,0.01,0.001, \ldots$ Contrary to those, the number $0 . \overline{0} 1$ will not become bigger when multiplied by ten. It can also be an alternative to the non-standard concept, as described by Katz and Katz (2010), where infinitely small quantities are arrived at by extending decimal expansions. These infinitely small quantities exist besides the classical real numbers in this theory (Ely, 2010).

The following two items of the dialogues focus on the geometrical context and it is gradually realized by the application of both points of view.

Task 7 (MAXIMDISTANCE): There is a given straight line $b$ and point $A$, which does not lie on this line. Construct segment $A B$ with point $B$, which lies on the given straight line $b$ with the segment $A B$ as long as possible. (The text is accompanies Fig. 1.)

The first answers:

- "B is in infinity."

- " $B$ is at the end of the straight line."

Initiation questions:

- "But the straight line does not end anywhere, so why does it lie behind that point B of yours?"

- "And what will happen when I shift point $A$ by a small move to the left? Will the segment $A B$ be longer?"

- "What angle does the segment $A B$ form with straight line $b$ ?"

- "Now I will drop a perpendicular line from point $A$ to the straight line $b$. I'll designate its heel as point $C$ and the centre of the segment $A C$ as $S$. How long will the segment $S B$ be? Will it be shorter, or as long as the segment $A B$ ?"

Roughly one-half of all the interviewed students were led by the first abovementioned question to a contradiction, since they reacted for instance as follows: "Then, there is still another point; then actually, only in it, does the segment end. But, actually, I can continue moving the point further and further." The second half of the students reacted with the answer that can be represented by the following words: "There is nothing there, it is the absolute last point on the straight line and there is nothing else behind it."

As far as the other initiation question is concerned, all students, apart from one, claimed that the new segment $A B$ would be longer. Only one student reacted with the following words: "The segment is infinitely long, this will not change." The answer in the majority of respondents bears testimony that these students, in spite of their previous reactions, are not in this context at the omega position. From the analysis of answers to previous items at the same time, it emerged that in the arithmetical context a considerable number of these students had been at 
the omega position. One of the possible explanations can be the fact that students, in the course of their common lessons of synthetic geometry, do not solve tasks in which it would be necessary to think about the position of the horizon and start moving it further. Neither has teaching analytical geometry, in which a straight line is parameterized by a set of real numbers, had any influence on this phenomenon.

With the third initiation question, students either used to answer saying that "the angle comes closer, in a limit way, to zero" or that "its size is an infinitely small number, the one we were talking about a short while ago."

Here the geometrical context was projected into an arithmetical context. The first answer indicates a procedural understanding of the problem; the other can refer to the omega position.

In the situation induced in the fourth initiation question, all students answered that segment $S B$ would be shorter than segment $A B$. One student reacted by means of the following words: "We could do such division of the segment into two halves into infinity and then these segments $S B$ would be nearly of the same lengths."

Based on the respondents' answers to the second and the fourth initiation questions, it is possible to hypothesize that with the exception of one student, no one finds himself in the omega position. The students' reactions correspond with their experience with finite objects, in this context based on primary intuition.

The second answer:

- A parallel line is suggested.

Initiation question:

- "And where will your straight line intersect with the straight line $b$ ?"

Answer 'A parallel line is suggested' was given by three respondents only. All of them reacted by means of the following words: "In infinity. Here also lies that point B."

With these three students, it was the case of the omega position. They did not even change their opinions in the subsequent debate. For these students a straight line is actually infinitely long. However, it has a boundary point. Jirotková and Littler (2004) in their research analysis interviews in which students suppose that parallel lines meet at this improper point in infinity. It is a sort of intuitive idea from projective geometry.

Task 8 (AREASQMIN): There is the square $A B C D$. Find the point $X$ on its $B C$ side so that the triangle $A B X$ will have the smallest possible area.

Answers:

- "It will be close above point $B$ " or it is drawn in this sense.

- "Closest to point B."

- $X$ is drawn slightly above point $B$.

Initiation question:

- "And what about the centre $S$ of the segment $B X$ ? Isn't the area of triangle $A B S$ even smaller?"

Roughly one third of all the interviewed students answered here that segment has $B X$ as its centre and that the area of triangle $A B S$ is even smaller than that of triangle $A B X$. After the discussion, they arrived at the conclusion that they will always find another point $X$, which lies on the side $B C$ and that it is consistently 
closer to point $B$. Conceptions of these students correspond with the phase of potential infinity.

Another third of the students reacted typically with the following words: "No, the segment $B X$ has no centre, that point $X$ lies close to point $B$, this is in fact the closest point to the point $B$." It resulted from the discussion with the respondents that the reason for this answer is not concealed in the above-mentioned obstacle Replacement of an object with its model, specifically here in the 'bead-like' idea of the point. Thus, with these students the omega position can be recognized.

The remaining students reach the following contradiction in the discussion: "Segment $B X$ is of infinitely small length, the distance between these points nearly equals zero; it cannot be determined, but the point is infinitely small, then actually that centre should still lie there." The established cognitive conflict, however, endures. It is a case of the so-called vain attempt at removing the cognitive conflict (Cihlár et al., 2009).

In chapter 5.1, it is hypothesized that students between at the ages $12-18$, leave the phase of natural infinity in the geometrical context more easily while applying the view into the depth than when applying view into the distance. Students do not need in the tasks they solve, in the majority of cases, the view into the distance. Statements from freshmen at universities confirm this view.

In conclusion, we wish to express our opinion concerning the mutual ratio of respondents who are in the phase of the omega position or in the phase of potential infinity. This ratio can differ according to the context, as well as the type of view. Estimates of relative frequencies can be seen in the following Fig. 6.

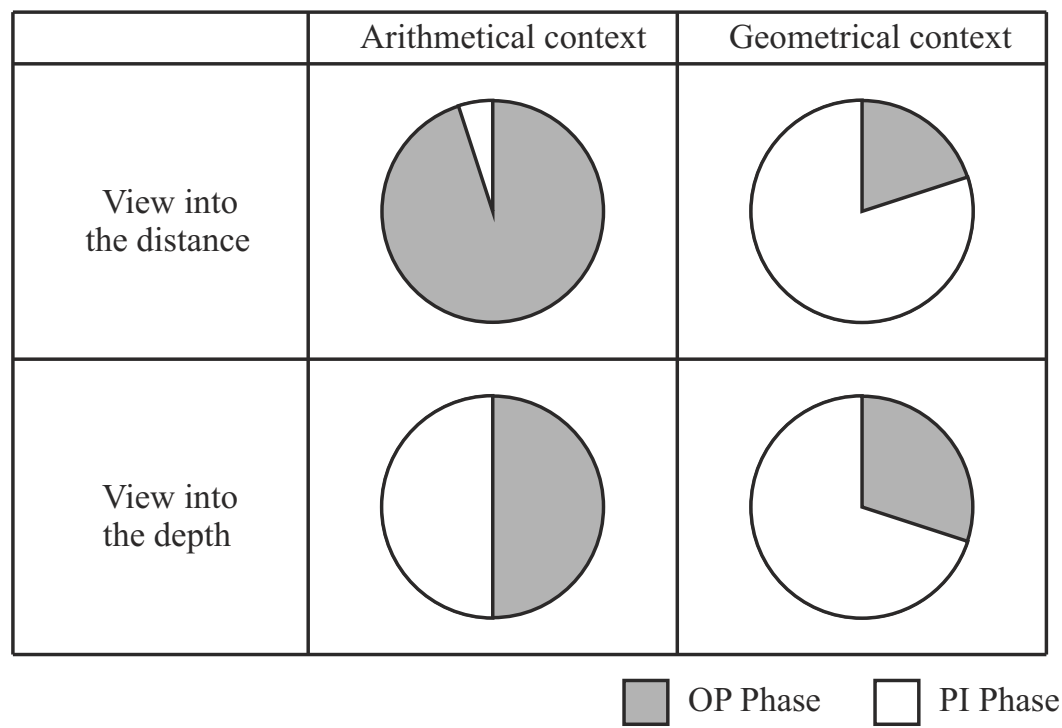

Fig. 6: Comparison of students' relative frequencies in the OP and PI phases

In the arithmetical context, more students find themselves in the omega position than in the geometric context. When applying the view into distance, more students find themselves in the arithmetical context than in the view into the depth, while in the geometrical context it is vice versa.

In order to have a complete picture, let us state at the end of this chapter that only two students out of the total number of twenty interviewed, have proved in three cases that their perception is, in this particular context, in the phase of actual infinity. 
The student Richard, in connection with Task 2 MINIMPOSITIV and Task 13 RATIOMLIMIT, stated that no such number exists: "But still, I will always find a smaller and smaller positive number or a smaller fraction than any number you will give me. The smallest number bigger than zero is nonsense."

The student Michal is completely clear about the geometrical context while looking into the distance. In connection with the Task 7 MAXIMDISTANCE, he says: "I cannot construct such a segment. By doing it I would change the straight line into a segment."

\section{Conclusions}

It has been discovered by virtue of this research, that it is necessary to extend the categorization of students' conception of infinity. Besides the phases of potential infinity (PI) and actual infinity (AI), it is also suitable to work with the phases of natural infinity (NI) and the omega position (OP).

The phase of natural infinity is, from the temporal point of view, its primary phase, when the learners' ideas are still at a lower level of abstraction and the phase is still often connected with real objects. Sets of numbers and points prove to be naturally infinite to them provided that they stretch as far as their horizons. The horizon in this case is fixed within the given time. The largest or the smallest positive numbers are those, which can be written down and named by the learners, they imagine a straight line as a very long segment; they can also conceive the idea of two neighbouring points on the line segment (just like two small beads on a string). They consider groupings consisting of numerous real objects, as infinite (little grains in the heap of sand).

Just as the horizons of human cognition used to shift in view into the distance or depth by means of a pair of binoculars or a microscope, the learners' horizons inch their way analogically during the course of the development of their mathematical ideas. They become gradually acquainted with larger and larger numbers, as well as smaller and smaller positive numbers. Provided that the learners have already accepted these facts, i.e. that to each of the positive numbers there exists another larger (or respectively a smaller) number and that the straight line can be 'arbitrarily extended', then they are in the phase of potential infinity. Their horizon is already transferable 'without any limitation', but it still lies within the set understood objectively as actually infinite.

Only when students 'break all horizons' in their conception, do they get into the phase of actual infinity. In their imagination they can work for example with a set of real numbers or even with a set of all the points of a straight line, which are understood as existing wholes.

The second part of our research, described in chapter 5.1, has brought a piece of knowledge that some students' ideas about infinity cannot be included into any of the three above-described phases. These ideas are again characterized by the appearance of a fixed horizon, but not within the framework of the set under consideration (as it happened with potential infinity), but outside of this objectively actually understood set - at its 'end'. A typical representative of these ideas is 'an infinitely large' or 'an infinitely small' number, or a point at the end of a straight line, etc. The association with ordinal numbers has induced us to giving a name to this new phase - the omega position. As the questionnaire used in the second part of our research did not enable us to distinguish unambiguously the phase of potential infinity from the 
omega position in individual students, we prepared interview scenarios, the results of which are described in chapter 5.2. These interviews, the scenarios of which provide us with an operative tool for the identification of the omega position (the second goal of our work), have proved that a significant number of students are in the omega position and these students work in their conceptions with infinity as a 'limit object' or with an improper element. Thus, the first research hypothesis H1 has been confirmed.

When comparing the results of chapters 5.1 and 5.2 , we can see that an interesting agreement starts to take form. Chapter 5.1 refers to proportional representation of pupils between the ages of $12-18$, who have already overcome the primary phase of natural infinity and at the same time they are not yet in the phase of actual infinity (the first part of the work). These students are therefore in the phase of potentional infinity or the omega position. In chapter 5.2, the estimates of the proportional representation of both the phases in university students are referred to, i.e. those starting their studies. In both the cases, higher frequencies are revealed in the arithmetical context with the view into the distance, but in the geometrical context, higher frequencies can be found with the view into the depth. We can see the causes for these phenomena (as described above) in the learners' experience with specific tasks in their mathematical schoolwork. The accord itself is then interpreted as follows: the conception of the movable horizon in given contexts and views (entering the PI phase) is just as difficult as its anchoring in an improper position (accepting the OP phase).

The second research hypothesis H2 supposed that the omega position is a transitional developmental phase between potential and actual infinity and that it is created predominantly by means of primary intuition, now when the individual is forced to change his potential approach to infinity to the actual one by applying a new context. This means that the potential approach can be an obstacle to actual understanding. The third part of this research, focused on interviews with students, however, has brought even another possibility that the omega position comes into existence by means of secondary intuition only after the students get some information about actual infinity. This hypothesis has been confirmed only partially, as one of the possibilities. Individual developmental paths of students' ideas about infinity thus can be depicted by the scheme in Fig. 7 .

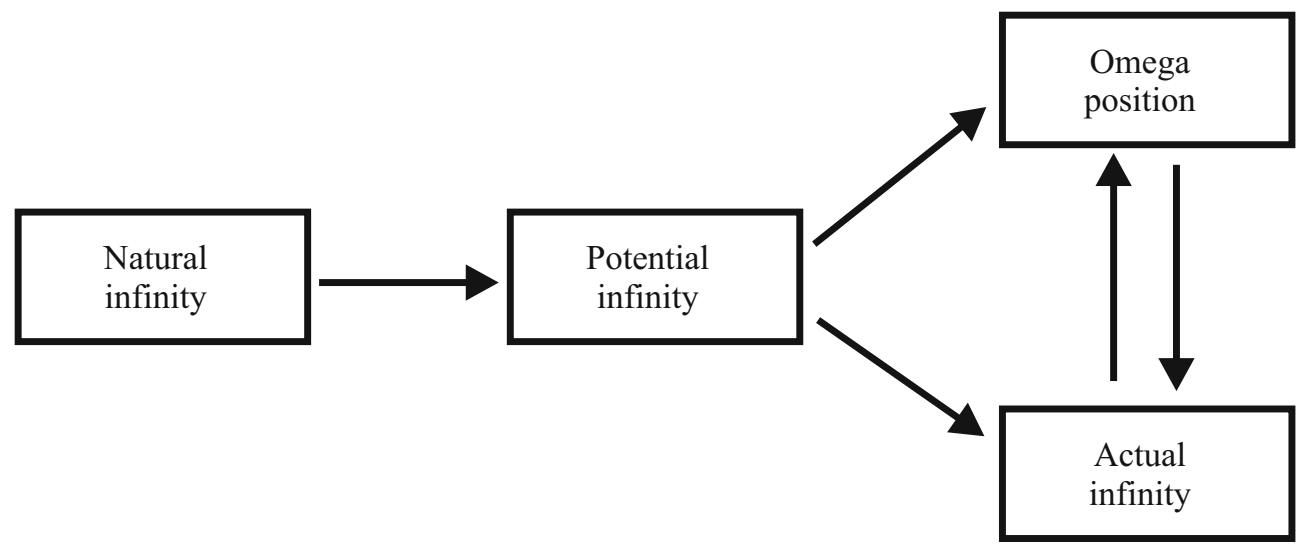

Fig. 7: The scheme of possible transitions between the phases of ideas of infinity

Taking into consideration that the research carried out so far has been, from the temporal point of view, a cross-sectional study, it would also be necessary to carry out a longitudinal study for the purpose of mapping the development of pupils' 
ideas. This is one of the possibilities for subsequent research. Another possibility is represented by the omega position research with dependence on age, the context and type of view. For further application of the research results in practice it would be useful to find out in what situations, in teaching university mathematics, the ideas at the level of the omega position are an obstacle and in which, on the contrary, they are effective.

\section{ACKNOWLEDGEMENT}

Preparation of the article has been supported by Grant No. 406/07/1026 of the Czech Republic Grant Agency.

\section{REFERENCES}

Bauer, L. (2011). Mathematik, Intuition, Formalisierung: eine Untersuchung von Schülerinnen- und Schülervorstellungen zu 0.9.9. Journal für Mathematik-Didaktik, 32(1), $79-102$.

Brousseau, G. (1997). Theory of didactical situations in mathematics: Didactique des mathématiques, 1970-1990. Boston: Kluwer Academic Publishers.

Brousseau, G. \& Sarrazy, B. (2002). Glossaire de quelques concepts de la théorie des situations didactiques en mathématiques. Bordeaux: DAEST, Université Bordeaux 2.

Brown, T. \& Heywood, D. (2010). Geometry, subjectivity and the seduction of language: the regulation of spatial perception. Educational Studies in Mathematics, 77, 351-367.

Cihlář, J., Eisenmann, P. \& Krátká, M. (2013). Forming the infinity concept through overcoming obstacles. Ústí nad Labem: UJEP.

Cihlář, J., Eisenmann, P., Krátká, M. \& Vopěnka, P. (2009). Cognitive conflict as a tool of overcoming obstacles in understanding infinity. Teaching Mathematics and Computer Science, 7, 279-295.

Conway, J. H. (2001). On numbers and games. London: Academic Press, 1976. Second edition: A. K. Peters, Wellesley/MA.

Dubinsky, E., Weller, K., McDonald, M. A. \& Brown, A. (2005a). Some historical issues and paradoxes regarding the concept of infinity: An APOS-Based Analysis, Part 1. Educational Studies in Mathematics, 58, 335-359.

Dubinsky, E., Weller, K., McDonald, M. A. \& Brown, A. (2005b). Some historical issues and paradoxes regarding the concept of infinity: An APOS-Based Analysis, Part 2. Educational Studies in Mathematics, 60, 253-266.

Edwards, B. S., Dubinsky, E. \& McDonald, M. A. (2005). Advanced mathematical thinking. Mathematical Thinking and Learning, 7, 15-25.

Ely, R. (2010). Nonstandard student conceptions about infinitesimals. Journal for Research in Mathematics Education, 41, 117-146.

Fischbein, E. (1987). Intuition in science and mathematics. Dodrecht: Reidel.

Fischbein, E. (2001). Tacit models and infinity. Educational Studies in Mathematics, 48, 309-329. 
Hannula, M., Pehkonen, E., Maijala, H. \& Soro, R. (2006). Students' understanding of infinity. In Teaching mathematics: retrospective and perspectives. Proceedings of the rth international conference (79-83). Tartu: Eritrea.

Jahnke, H. N. (2001). Cantor's cardinal and ordinal infinities: An epistemological and didactic view. Educational Studies in Mathematics, 48, 175-197.

Jirotková, D. \& Littler, G. (2004). An insight into pupils' understanding of infinity in a geometrical context. In Proceedings of the $28^{\text {th }}$ Conference of the International Group for the Psychology of Mathematics Education (97-104), Bergen: Univ. College.

Juter, K. (2006). Limits of functions as they developed through time and as students learn them today. Mathematical Thinking and Learning, 8, 407-431.

Katz, K. U. \& Katz, M. G. (2010). Zooming in on infinitesimal 1-.9. . in a post-triumvirate era. Educational Studies in Mathematics, 74, 259-273.

Katz, V., Dorier, J. L., Bekken, O. \& Sierpinska, A. (2000). The role of historical analysis in predicting and interpreting students' difficulties in mathematics. In J. Fauvel \& J. V. Maanen (Eds.), History in Mathematics Education (149-161). Dordrecht: Kluwer Academic Publisher.

Kidron, I. (2011). Tacit models, treasured intuitions and the discrete - continuous interplay. Educational Studies in Mathematics, 78, 109-126.

Kidron, I. \& Tall, D. (2015). The roles of visualization and symbolism in the potential and actual infinity of the limit process. Educational Studies in Mathematics, 88, 183-199.

Krátká, M. (2005). A geometrical picture as an obstacle. In Proceedings of SEMT'05 (179-186). Praha: UK PedF.

Krátká, M. (2010). Zdroje epistemologických překážek v porozumění nekonečnu. Scientia in educatione, 1(1), 187-100.

Monaghan, J. (2001). Young people's ideas of infinity. Educational Studies in Mathematics, 48, 239-257.

Piaget, J. (1977). The development of thought: Equilibration of cognitive structures. New York: The Viking Press.

Radford, L., Boero, P., \& Vasco, C. (2000). Historical formation and student understanding of mathematics: Epistemological assumptions framing interpretations of students understanding of mathematics. In J. Fauvel \& J. Van Maanen (Eds.), History in mathematics education. Dordrecht: Kluwer Academic Publisher.

Robinson, A. (1996). Nonstandard analysis. Princeton University Press.

Sierpinska, A. (1994). Understanding in mathematics. Washington, D.C.: The Falmer Press London.

Singer, F. M. \& Voica, C. (2008). Between perception and intuition: Learning about infinity. The Journal of Mathematical Behavior, 27, 188-205.

Swan, M. (1983). Teaching decimal place value. A comparative study of conflict and positive only approaches. Nottingham: University of Nottingham, Shell Centre for Mathematical Education.

Tall, D. O. (1976). Conflicts and catastrophes in the learning of mathematics, Mathematical Education for Teaching, 2(4), 2-18.

Tall, D. O. (1977). Cognitive conflicts and the learning of mathematics. In Proceedings of PME 1, Utrecht. 
Tall, D. O. (1991). The psychology of advanced mathematical thinking. In D. Tall (Ed.), Mathematics Education Library: Vol. 11 Advanced Mathematical Thinking. (3-21).

Dordrecht: Kluwer Academic Publisher.

Tall, D. (2001). Natural and formal infinities. Educational Studies in Mathematics, 48, $199-238$.

Tall, D. O. (2009). Dynamic mathematics and the blending of knowledge structures in the calculus. ZDM. The International Journal on Mathematics Education, 41, 481-492.

Tall, D. \& Tirosh, D. (2001). Infinity - the never-ending struggle. Educational Studies in Mathematics, 48, 129-136.

Tall, D. \& Vinner, S. (1981). Concept image and concept definition in mathematics with particular reference to limit and continuity. Educational Studies in Mathematics, 12, 151-169.

Tsamir, P. (2001). When "The Same" is not perceived as such: The case of infinity sets. Educational Studies in Mathematics, 48, 289-307.

Vamvakoussi, X. \& Vosniadou, S. (2004). Understanding the structure of the set of rational numbers: a conceptual chase approach. Learning and Instruction, 14, 453-467.

Vopěnka, P. (2011). Velká iluze matematiky XX. století a nové základy. Plzeň: Vydavatelství Západočeské univerzity v Plzni.

Yopp, D. A., Burroughs, E. A. \& Lindaman, B. J. (2011). Why it is important for in-service elementary mathematics teachers to understand the equality $.999 \ldots=1$. Journal of Mathematical Behavior, 30, 304-318.

JIŘÍ CiHLÁř, jiri.cihlar@ujep.cz

Petr Eisenmann, petr.eisenmann@ujep.cz

MAGDALENA KRÁTKÁ, magdalena.kratka@ujep.cz

UJEP v Ústí nad Labem, PřF

Katedra matematiky

České mládeže 8, Ústí nad Labem, Czech Republic 